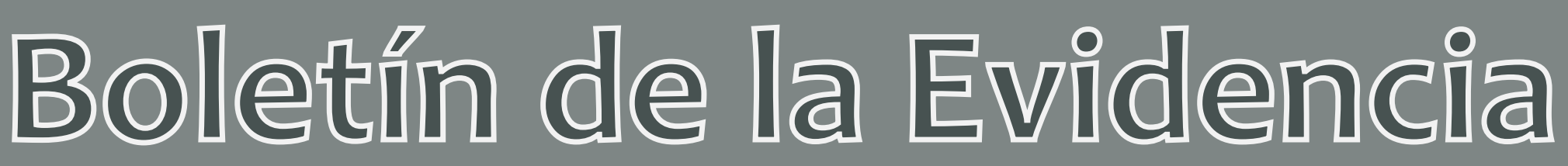

Mayo-junio, $2021 \quad$ Suplemento 3 Vol. 3 Núm 1. ISSN: 2683-1422

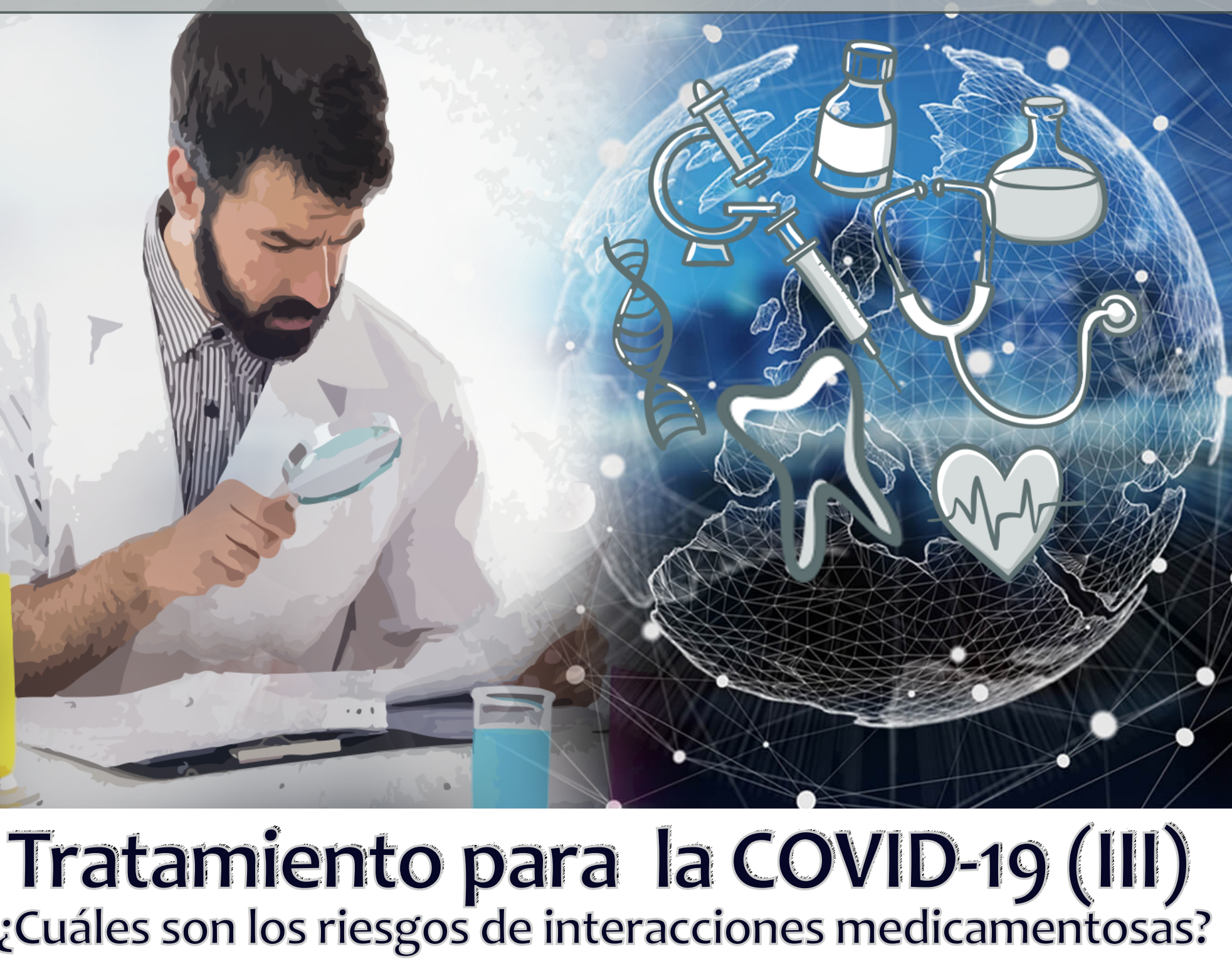

\title{
*Osvaldo Castelán-Martínez
}

Ante la situación emergente de la pandemia de la COVID-19, el tratamiento que se ha ensayado en las diferentes etapas clínicas con frecuencia no considera los riesgos de la polifarmacia e interacciones medicamentosas (IM). En este sentido, no debemos perder de vista que un alto porcentaje de los pacientes diagnosticados con COVID-19 cursa con comorbilidad de enfermedades crónicas no trasmisibles, tales como la diabetes mellitus, hipertensión arterial sistémica, artropatías y enfermedades psiquiátricas entre otras, cuyos pacientes tienen indicado de manera crónicas varios medicamentos que potencialmente podrían tener IM con los que se administran para la COVID-19, asimismo, los pacientes que presentan

\footnotetext{
*Profesor de Tiempo Completo Asociado C de la carrera de QFB de la FES Zaragoza, UNAM. E-mail: castelan@unam.mx
}

D.R. @ Castelán-Martínez OD. Tratamiento para la COVID-19 (III) ¿Cuáles son los riesgos de interacciones medicamentosas? CyRS. 2021;3

(1 Suppl. 2): 1-14. DOl:https:/doi.org/10.22201/fesz.26831422e.2021.3.1_suppl_3 


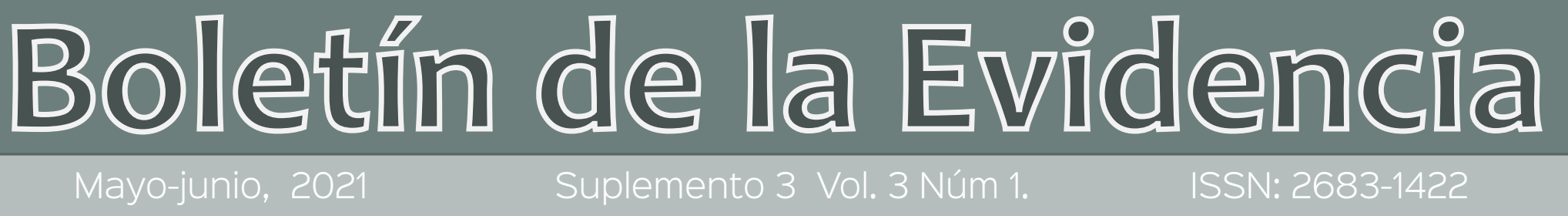

un cuadro grave de esta enfermedad requieren varios medicamentos que podrían tener un riesgo de IM.

En este contexto, en este último Boletín de la serie Tratamiento para la COVID-19, se presenta los medicamentos más utilizados para la enfermedad, algunos mecanismos farmacológicos y los principales riesgos de IM:

\section{FÁRMACOS PROPUESTOS PARA LA COVID-19}

A un año de la declaratoria de pandemia por COVID-19, las opciones terapéuticas son limitadas. Los tratamientos principales utilizados se describen a continuación, aunque la evidencia que respalda el uso de estas intervenciones no es sustancial, está en investigación o en algunos casos es contradictoria. ${ }^{1}$

\section{Antivirales}

El genoma de SARS-2 es un ARN de una sola cadena, por esta razón, los antivirales desarrollados para tratar ARN-virus, como el virus del Ébola y los virus influenza, fueron de los primeros fármacos en ser propuestos para su tratamiento. Los fármacos análogos de nucleósidos como el remdesivir, el favipiravir, la ribavirina y el sofosbuvir tienen su acción antiviral mediante la interferencia de la actividad de la ARN polimerasa dependiente de ARN, cuya función es incorporar ribonucleótidos en cadenas de ARN viral naciente. Estos antivirales confunden a la ARN polimerasa viral que se traduce en un retraso en la síntesis o en la terminación prematura de las cadenas de ARN que conduce a la inhibición en la producción y la replicación del ARN viral. Desde mayo de 2020, la FDA aprobó el uso de emergencia del remdesivir para pacientes adultos y pediátricos mayores de 12 años hospitalizados con enfermedad severa. ${ }^{2}$ Sin embargo, el ensayo Solidaridad patrocinado por la Organización Mundial de la Salud (OMS) no mostró beneficio para los pacientes hospitalizados con COVID-19 que recibieron remdesivir. ${ }^{3}$ En este sentido, recientemente (marzo de 2021), la Comisión Federal para la Protección Contra Riesgos Sanitarios (COFEPRIS), autorizó para el uso de emergencia del remdesivir, para el tratamiento de pacientes hospitalizados y de alta especialidad en casos tempranos de la COVID-19. ${ }^{4}$ El uso de favipiravir, ribavirina y el sofosbuvir se encuentran en estudio en diversos ensayos clínicos. En México, solo la ribavirina y el sofosbuvir cuentan con registro sanitario.

D.R. @ Castelán-Martínez OD. Tratamiento para la COVID-19 (III) ¿Cuáles son los riesgos de interacciones medicamentosas? CyRS. 2021;3 (1 Suppl. 2):1-14.DOl:https://doi.org/10.22201/fesz.26831422e.2021.3.1_suppl_3 
in vitro, la ivermectina exhibió propiedades antivirales contra SARS-2 a través de la inhibición de la importación nuclear de proteínas virales mediada por IMPa/ $\beta 1$. Una revisión sistemática y metaanálisis de estudios observacionales con pocos participantes y con una calidad de la evidencia baja mostró un beneficio en reducir la mortalidad. ${ }^{6}$ Empero, es necesario que ensayos clínicos aleatorizados confirmen el papel benéfico de la ivermectina.

De forma similar, la nitazoxanida es un antiparasitario que ha mostrado tener actividad in vitro en contra diversas familias de virus. En México, un estudio prospectivo no controlado exploró su eficacia en tres diferentes escenarios clínicos mostrando un beneficio discreto en los pacientes ambulatorios. ${ }^{7}$ Sin embargo, el bajo número de pacientes y la tasa de mortalidad relativamente alta no apoyan el uso de la nitazoxanida contra la COVID-19. Además, estudios con un mayor número de pacientes son necesarios para dar solidez a la evidencia para avalar su uso.

\section{Inmunomoduladores}

El interferón alfa-2b (IFNa-2b) es un fármaco utilizado para tratar enfermedades virales como el sarcoma de Kaposi relacionado con el SIDA, así como hepatitis crónica B y C. EI IFNa-2b es un inhibidor de la replicación viral y de las proteasas virales; además, aumenta la actividad fagocítica de los macrófagos y la citotoxicidad específica de los linfocitos contra las células infectadas. Actualmente, se explora en ensayos clínicos el potencial terapéutico del IFN-2b para la COVID-19.

\section{Anticuerpos monoclonales}

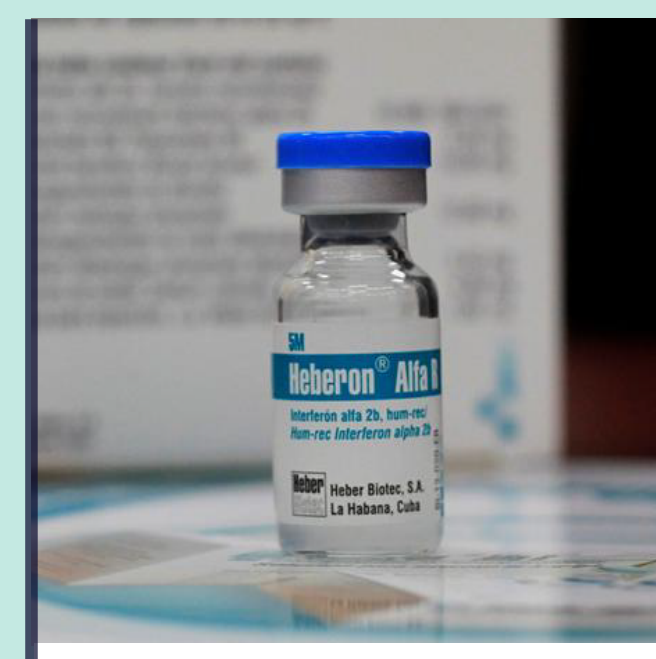

Figura 3. Heberon

\section{El ensayo} de fase III CONVACTA demostró que el tocilizumab carecía de utilidad para el tratamiento de pacientes con COVID-19.8

El virus que causa la COVID-19 se une a las células epiteliales alveolares y activa tanto el sistema inmunológico innato como el adaptativo, lo que conduce a la liberación de una gran cantidad de citocinas. Entre éstas, la IL-6 aumenta la permeabilidad vascular, lo que permite que una gran cantidad de fluidos corporales y células sanguíneas entren en los alvéolos pulmonares que conduce a disnea e insuficiencia respiratoria. Bajo esta premisa, el tocilizumab es un anticuerpo monoclonal humanizado que se une a los receptores de IL-6 solubles y unidos a la membrana, en consecuencia, inhibe la vía de señalización de IL-6. Sin embargo, el ensayo de fase III CONVACTA demostró que el tocilizumab carecía de utilidad para el tratamiento de pacientes con COVID-19. ${ }^{8}$ En contraste, tocilizumab puede conducir a inmunosupresión y su toxicidad puede limitar su uso.

El sarilumab, es un anticuerpo monoclonal humano que bloquea el receptor de IL-6 que se utiliza para el tratamiento de la artritis reumatoide y que actualmente se encuentra en ensayos clínicos para 


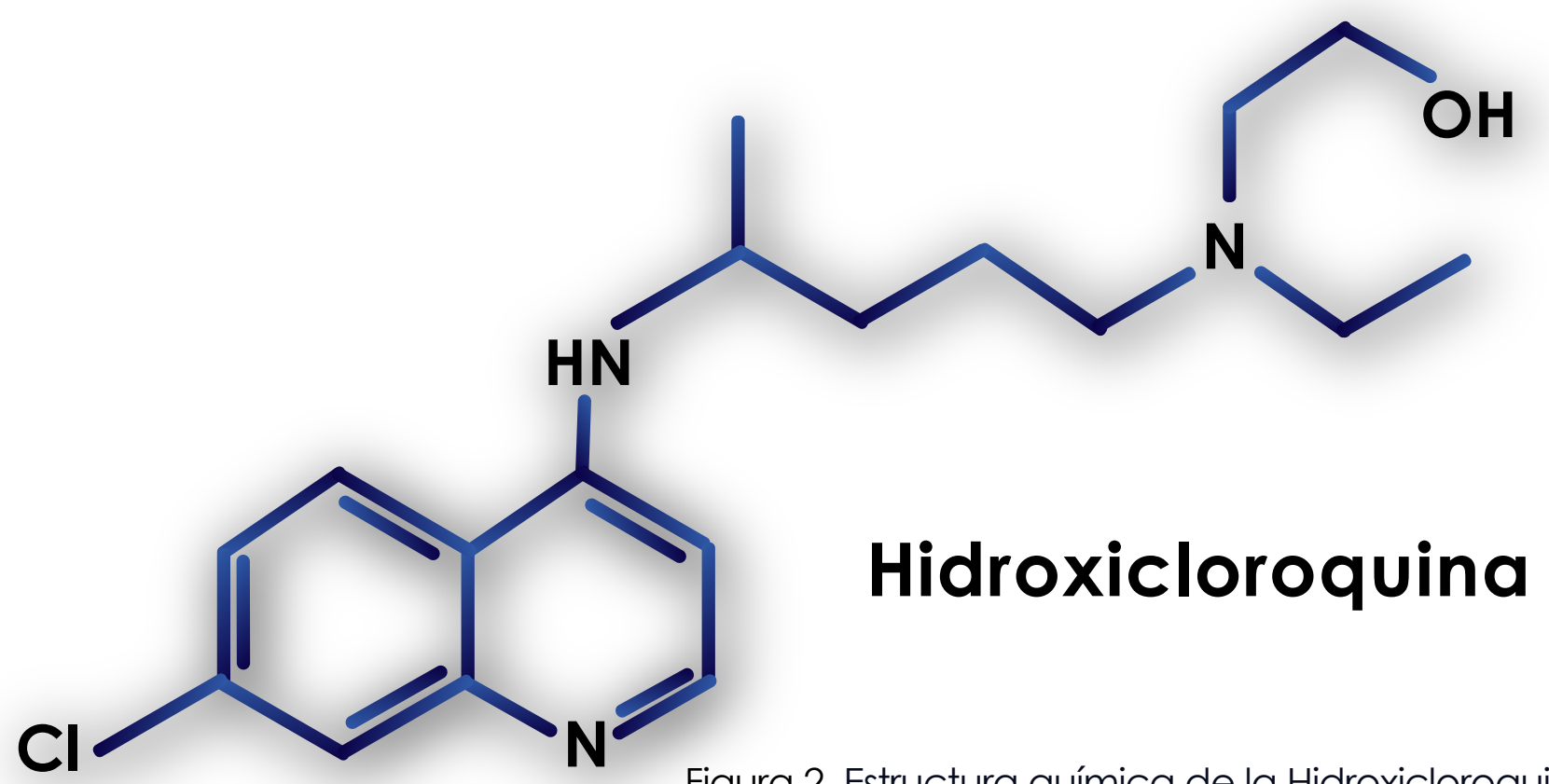

Figura 2. Estructura química de la Hidroxicloroquina

El lopinavir y el ritonavir son inhibidores de la aspartil-proteasa del VIH, enzima clave en la formación de nuevos viriones. Aunque los coronavirus codifican una clase diferente de proteasa, la cisteína-proteasa, los estudios de investigación han demostrado que ambos fármacos son eficaces contra los virus SARS y MERS. No obstante, los ensayos clínicos que utilizan tanto lopinavir como ritonavir en pacientes infectados con SARS-2 han mostrado beneficios escasos para mejorar el resultado clínico.

\section{Inhibidores de la entrada viral}

La hidroxicloroquina es un agente inmunosupresor que se usa para tratar diversos trastornos autoinmunitarios, como la artritis reumatoide, el síndrome de Sjogren y el lupus eritematoso sistémico. La hidroxicloroquina también se usa como un potente fármaco antiparasitario y se ha descrito que tiene un efecto antiviral inespecífico. Para el tratamiento de la COVID-19 se ha propuesto que la hidroxicloroquina inhibe la glicosilación terminal del receptor ACE2 y que de esta manera bloquea la entrada del virus, la infección y la progresión de la enfermedad. No obstante, los ensayos clínicos no han mostrado beneficio en reducir la mortalidad y el tiempo de recuperación de la enfermedad. En contraste, la hidroxicloroquina tiene riesgo de reacciones adversas que incluyen arritmias cardiacas serias, trastornos sanguíneos y del sistema linfático, lesiones renales y problemas e insuficiencia hepática que han conducido a que la FDA haya retirado la aprobación de uso de emergencia. ${ }^{5}$

La ivermectina es un fármaco antiviral/antiparasitario de amplio espectro aprobado por la FDA. En estudios 
el tratamiento de pacientes con COVID-19 en estado crítico, ya sea solo o en combinación con hidroxicloroquina, azitromicina y/o corticosteroide.

Inhibidores de la quinasa de Janus (JAK, por sus siglas en inglés)

Varios síntomas de COVID-19, como edema e insuficiencia pulmonares, daño hepático, cardíaco y renal, están asociados con la tormenta de citocinas, que manifiesta niveles séricos elevados de IL-17. Tanto la IL-6 como la IL-23 activan STAT3 a través de JAK2, que luego promueve la expresión de IL-17. El baricitinib es un inhibidor selectivo y reversible de JAK1 y JAK2 que está aprobado para el tratamiento de la artritis reumatoide. Para la COVID-19, se ha sugerido que el baricitinib previene la liberación de citocinas proinflamatorias. Diversos ensayos clínicos están probando la eficacia del baricitinib en combinación con medicamentos antivirales,

así como su papel como un tratamiento de apoyo.

\section{Suplementos nutricionales}

Un sistema inmunológico en buen funcionamiento es crucial para responder adecuadamente a la infección por SARS-2. Diversos nutrientes se encuentran involucrados en la homeostasis del sistema inmune y su utilidad en el tratamiento de la COVID-19 está en estudio. El aumento en la inmunidad por el consumo de vitamina $C$ al estimular la producción de IFN, incrementa la proliferación de linfocitos y mejora la capacidad fagocítica de los neutrófilos. La vitamina $D$, una hormona que juega un papel importante en la inmunidad adaptativa, así como en la diferenciación, proliferación y maduración de las células inmunes, también ha sido propuesta para la prevención y coadyuvante terapéutico.

\section{Antiinflamatorios}

La metilprednisolona es un fármaco antiinflamatorio esteroideo que se usa para tratar enfermedades como lupus, artritis, psoriasis y colitis ulcerosa. La metilprednisolona puede ayudar al tratamiento de la COVID-19 mediante sus mecanismos de acción que incluyen la inhibición de la actividad de la fosfolipasa A2 que a su vez previene la formación de ácido araquidónico, la inhibición de la activación de NF-kB y de otros factores de transcripción inflamatorios. El naproxeno, es un analgésico no esteroideo que tiene actividad en contra el 
virus de la influenza $A$. El naproxeno también es un inhibidor de la COX no selectivo que disminuye la síntesis de prostaglandinas, así como los mediadores inflamatorios inducidos por en la COVID-19. Por estas razones, tanto la metilprednisolona como el naproxeno se encuentran en ensayos clínicos de Fase 2 y 3 para el tratamiento de pacientes críticos con COVID-19.

La dexametasona es un glucocorticoide sintético que actúa como antiinflamatorio e inmunosupresor. En pacientes hospitalizados con COVID-19 que requieren oxigenación suplementaria o que estén en ventilación mecánica, el uso de dexametasona ha mostrado disminuir la mortalidad en comparación con los pacientes que solo recibieron tratamiento de soporte estándar. Sin embargo, la dexametasona debe ser utilizada con precaución y solo debe prescribirse en pacientes sin contraindicaciones que representen un riesgo, así como no debe prescribirse en pacientes ambulatorios que no requieren de oxigenación complementaria. ${ }^{9}$

\section{Mecanismos diversos}

La azitromicina, es un antibiótico macrólido que se usa para tratar una amplia gama de infecciones bacterianas, incluidas las infecciones de la familia Streptococcus, las producidas por clamidia y la gonorrea. La azitromicina interrumpe el crecimiento bacteriano bloqueando la síntesis de proteínas bacterianas mediante la interferencia de la traducción del ARNm. Los estudios preclínicos han encontrado que este antibiótico macrólido puede ejercer efectos antivirales contra el virus del Zika, el rinovirus y el virus del Ébola. Sin embargo, la azitromicina no ha demostrado tener eficacia para tratar la COVID-19, en consecuencia, muchas agencias regulatorias, incluida la COFEPRIS, no han aprobado su uso de emergencia.

La colchicina es un compuesto antiinflamatorio utilizado para tratar o prevenir los ataques de gota. Además, tiene propiedades antivirales contra la familia de virus Flaviviridae y reduce la replicación viral inhibiendo la formación de microtúbulos. La colchicina se encuentra actualmente en ensayos clínicos para el tratamiento de la COVID-19.

La ciclosporina A es un fármaco inmunosupresor que se utiliza principalmente para el tratamiento del rechazo de órganos después del trasplante. La ciclosporina es un inhibidor de la calcineurina que se une a los receptores de ciclofilina, lo que provoca la formación del complejo ciclosporina-ciclofilina, 
que luego también inhibe la vía de la IL-2 dependiente del calcio en las células. Recientemente, un grupo de investigación mexicano describió una disminución en la mortalidad en pacientes con COVID-19 de moderado a severo que recibieron una combinación de ciclosporina A con esteroides a bajas dosis. Empero, ninguna autoridad regulatoria ha brindado su autorización de uso de emergencia a esta combinación terapéutica. ${ }^{10}$ Otros ensayos clínicos están evaluando si la ciclosporina A sola o en combinación con otros medicamentos como metilprednisona y tacrolimus pueden ser de utilidad para el tratamiento del nuevo coronavirus.

En pacientes hospitalizados por

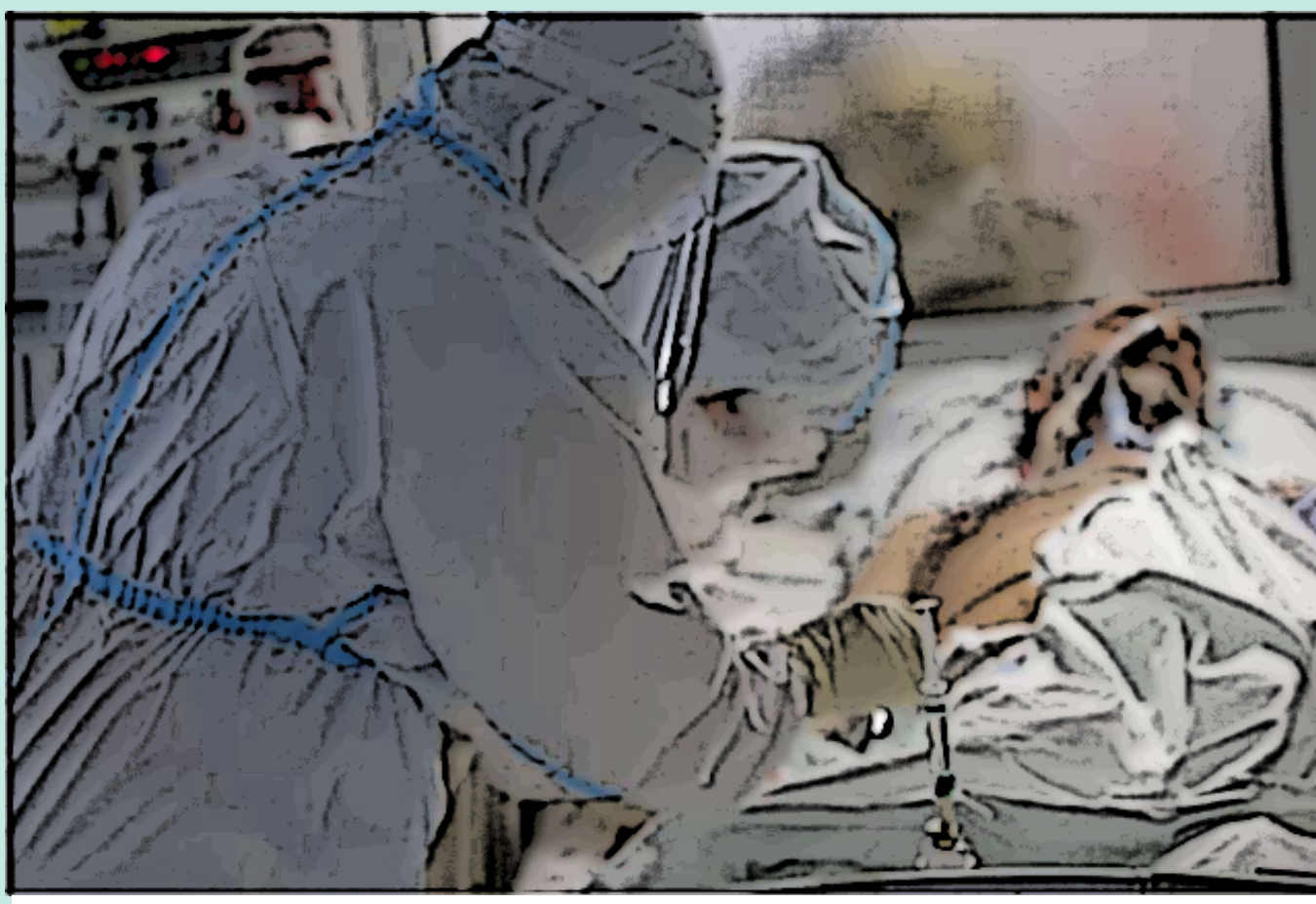

Figura 6. Tratamiento de paciente grave con COVID-19
COVID-19 se recomienda la trom-

boprofilaxis a su ingreso con enoxaparina o alguna otra heparina de bajo peso molecular incluida la heparina no fraccionada, en especial en los pacientes que con coagulopatía inducida por sepsis o con trombosis confirmada en cualquier localización. Para los pacientes con la enfermedad leve y tratamiento ambulatorio, no existe evidencia que sustente el uso de anticoagulantes (orales o parenterales) ni antiagregantes de plaquetarios para prevenir trombosis. ${ }^{11}$

El omeprazol es un inhibidor de la bomba de protones que se usa para tratar la enfermedad por reflujo gastroesofágico, la acidez de estómago y las úlceras. Mientras que el disulfiram es un inhibidor competitivo del receptor de benzodiazepinas periférico, así como de la enzima acetaldehído deshidrogenasa. Aunque se desconoce el mecanismo, de ambos fármacos en el tratamiento de COVID-19, tanto el omeprazol como el disulfiram se encuentran en ensayos clínicos.
Si bien es desesperante que no se tenga identificado un tratamiento innovador eficaz para la COVID-19, es necesario continuar con el análisis en profundidad de la evidencia científica que surge todos los días para identificar las terapias farmacológicas que potencialmente sean útiles para tratar esta enfermedad, ya sea de forma individual o en combinación.

\section{INTERACCIONES MEDICAMENTOSAS}

La urgencia de identificar terapias óptimas para el tratamiento de pacientes con COVID-19 ha conducido a que muchos equipos médicos prescriban medicamentos con evidencia clínica limitada. Sin embargo, el uso de los medicamentos fuera de indicación terapéutica (Off-label) conlleva desafíos importan- 
tes en el tratamiento, debido a la diversidad de escenarios clínicos en los cuales se emplean. En este sentido, la administración de varios fármacos al mismo tiempo o la administración de un número excesivo de fármacos, fenómeno conocido como polifarmacia, se presenta con mayor frecuencia en pacientes ancianos y pacientes con múltiples comorbilidades. En consecuencia, los pacientes que están recibiendo múltiples fármacos corren el riesgo de presentar una $\mathrm{IM} .^{12}$ Por tal motivo, las IM es un riesgo potencial durante el tratamiento para la COVID-19, debido al número y tipo de medicamentos indicados para la enfermedad, además de los fármacos que esté consumiendo el paciente por comorbilidades. Al respecto, las IM pueden conducir a la aparición de reacciones adversas a los medicamentos (RAM), antagonismo o sinergia de los efectos de los fármacos, que contribuyen a un mal pronóstico clínico y mayor riesgo de muerte de los pacientes afectados.

Los pacientes con comorbilidades como la enfermedad cardiovascular, la hipertensión arterial, la diabetes mellitus, la obesidad, la enfermedad renal crónica y la EPOC tienen más riesgo de presentar las formas más graves de la COVID-19 y mayor letalidad. No obstante, el riesgo potencial de IM se desconoce en gran medida debido a que la mayoría de los ensayos clínicos sobre COVID-19 no proporcionan detalles sobre la interacción entre los fármacos utilizados en el curso de esta enfermedad y los medicamentos concomitantes utilizados para el tratamiento de otras comorbilidades en estos pacientes.

Una alternativa es evaluar el riesgo de interacción mediante un análisis in silico (simulación computacional), para predecir el riesgo potencial de interacción basados tanto en la farmacocinética como en la farmacodinamia de la combinación de diversos fármacos. Al respecto, la Universidad de Liverpool puso a disposición una herramienta de acceso libre (www.covid19-druginteractions.org) que permite la evaluación gratuita del riesgo potencial de interacción entre las principales familias de medicamentos como son los antiarrítmicos, antihipertensivos, anticoagulantes, hipoglucemiantes, medicamentos para reducir los lípidos (estatinas) y broncodilatadores con los medicamentos utilizados en el tratamiento de los pacientes con COVID-19. ${ }^{13}$

En esta revisión, evaluamos las potenciales IM de la administración concomitante de fármacos que se encuentran en investigación para tratar la COVID-19 (Cuadro 1) y las IM de la coadministración de los mismos fármacos anti-COVID-19 y fármacos comúnmente utilizados para tratar enfermedades en pacientes mexicanos (Cuadro 2). Las IM potenciales fueron clasificadas en cuatro grupos: (1) no se espera una interacción clínicamente significativa; (2) interacción potencial que probablemente sea de 
Cuadro 1. Posibles Interacciones fármaco-fármaco entre los medicamentos utilizado en diversos ensayos clínicos para tratar la COVID-19

\begin{tabular}{|c|c|c|c|c|c|c|c|c|c|c|c|c|c|c|c|c|c|c|}
\hline Fármaco & 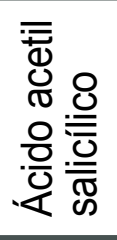 & 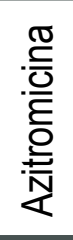 & 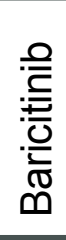 & $\begin{array}{l}\frac{\nwarrow}{0} \\
\cdot \frac{}{0} \\
\frac{0}{0} \\
\frac{0}{0} \\
\frac{0}{0}\end{array}$ & $\begin{array}{l}\frac{0}{C} \\
\frac{.}{0} \\
\frac{0}{0} \\
0 \\
0\end{array}$ & 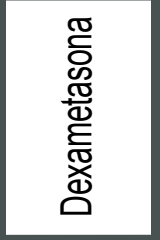 & 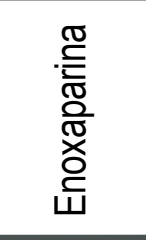 & $\begin{array}{l}\text { 을 } \\
\text { 흥 } \\
\text { 음 } \\
\text { 응 } \\
\text { 호 }\end{array}$ & 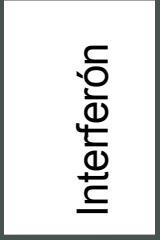 & 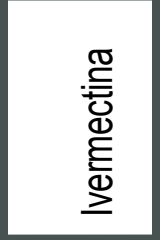 & 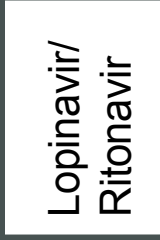 & 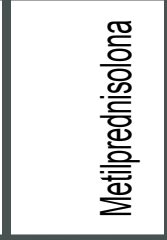 & $\begin{array}{l}\frac{0}{\bar{d}} \\
\frac{1}{2} \\
\frac{0}{0} \\
\frac{0}{1}\end{array}$ & 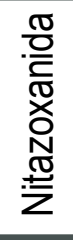 & 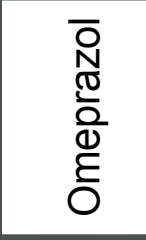 & 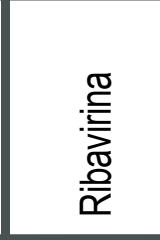 & 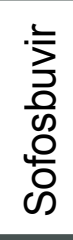 & 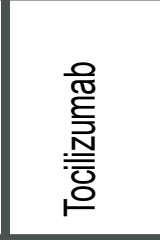 \\
\hline $\begin{array}{l}\text { Ácido } \\
\text { acetil } \\
\text { salicílico }\end{array}$ & & & & & & $\begin{array}{c}\text { Aumento } \\
\text { del riesgo } \\
\text { de } \\
\text { ulceración }\end{array}$ & $\begin{array}{l}\text { Riesgo } \\
\text { de } \\
\text { sangrado }\end{array}$ & & & & & & & & & & & \\
\hline Azitromicina & & & & $\begin{array}{c}\uparrow \text { de los } \\
\text { niveles } \\
\text { plasmáticos } \\
\text { de } \\
\text { ciclosporina }\end{array}$ & & & & $\begin{array}{c}\text { Riesgo de } \\
\text { prolongación } \\
\text { del intervalo } \\
\text { QT }\end{array}$ & & & $\begin{array}{l}\text { Riesgo de } \\
\text { arritmias } \\
\text { cardiacas }\end{array}$ & & & & & & & \\
\hline Baricitinib & & & & $\begin{array}{l}\text { Riesgo } \\
\text { de } \\
\text { inmuno- } \\
\text { supresión } \\
\text { aditiva }\end{array}$ & & & & $\begin{array}{l}\text { Posible } \\
\text { toxicidad } \\
\text { aditiva }\end{array}$ & $\begin{array}{l}\text { Riesgo de } \\
\text { toxicidad } \\
\text { hematológica } \\
\text { aditiva }\end{array}$ & & & & & & & $\begin{array}{l}\text { Riesgo de } \\
\text { toxicidad } \\
\text { hematológica } \\
\text { aditiva }\end{array}$ & & $\begin{array}{l}\text { Riesgo de } \\
\text { inmunosupresión } \\
\text { aditiva }\end{array}$ \\
\hline Ciclosporina A & & & & & $\begin{array}{c}\text { Riesgo de } \\
\text { miopatíay } \\
\text { rabdomiólisis. } \\
\text { No usar en } \\
\text { pacientes con } \\
\text { daño renal o } \\
\text { hepática }\end{array}$ & $\begin{array}{c}\downarrow \text { niveles } \\
\text { de } \\
\text { ciclosporina }\end{array}$ & & $\begin{array}{c}\uparrow \text { de los } \\
\text { niveles } \\
\text { de } \\
\text { ciclosporina }\end{array}$ & & $\begin{array}{l}\uparrow \text { niveles de } \\
\text { ivermectina en } \\
\text { cerebroy } \\
\text { aumenta el } \\
\text { riesgo de } \\
\text { neurotoxicidad }\end{array}$ & $\begin{array}{c}\uparrow \text { niveles } \\
\text { plasmáticos } \\
\text { de } \\
\text { ciclosporina }\end{array}$ & $\begin{array}{l}\text { Riesgo de } \\
\text { nefrotoxicidad } \\
\text { por } \\
\text { ciclosporina. }\end{array}$ & $\begin{array}{l}\text { Riesgo de } \\
\text { nefrotoxicidad } \\
\text { por } \\
\text { ciclosporina }\end{array}$ & & $\begin{array}{c}\uparrow \text { niveles } \\
\text { plasmáticos } \\
\text { de } \\
\text { ciclosporina }\end{array}$ & & & $\begin{array}{l}\text { La dosis } \\
\text { de ciclospo } \\
\text { rina puede } \\
\text { requerir } \\
\text { ser ajustada }\end{array}$ \\
\hline Colchicina & & & & & & $\begin{array}{c}\downarrow \text { de los } \\
\text { niveles } \\
\text { plasmáticos } \\
\text { de colchicina }\end{array}$ & & $\begin{array}{l}\text { ide los niveles } \\
\text { plasmáticos de } \\
\text { colchicina. La } \\
\text { combinación } \\
\text { está } \\
\text { contraindicada } \\
\text { en pacientes } \\
\text { con insuficiencia } \\
\text { renal o hepáácica }\end{array}$ & & & $\begin{array}{l}\text { ^ de los niveles } \\
\text { plasmáticos de } \\
\text { colchicina. } \\
\text { Contraindicado } \\
\text { en pacientes } \\
\text { con } \\
\text { insuficiencia } \\
\text { renal o hepática. }\end{array}$ & & & & & & & \\
\hline Dexametasona & & & & & & & & $\begin{array}{c}\text { Mayor } \\
\text { riesgo } \\
\text { de miopatías }\end{array}$ & & & & & $\begin{array}{l}\text { Posible aumento } \\
\text { de la incidencia } \\
\text { ylo la gravedad } \\
\text { de las úlceras } \\
\text { gasstrointestinales }\end{array}$ & & & & & \\
\hline
\end{tabular}


Cuadro 1. Posibles Interacciones fármaco-fármaco entre los medicamentos utilizado en diversos ensayos clínicos para tratar la COVID-19

\begin{tabular}{|c|c|c|c|c|c|c|c|c|c|c|c|c|c|c|c|c|c|c|}
\hline Fármaco & 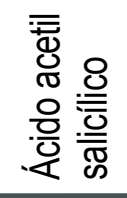 & 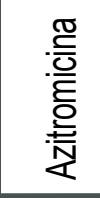 & 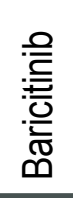 & 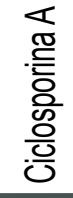 & $\begin{array}{l}\frac{\pi}{0} \\
\frac{0}{0} \\
\frac{0}{0} \\
0 \\
0\end{array}$ & 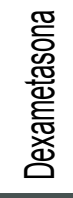 & 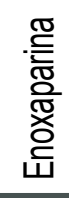 & $\begin{array}{l}\text { 뜰 } \\
\text { 흠 } \\
\text { 흫 } \\
\text { 흔 }\end{array}$ & 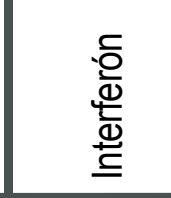 & 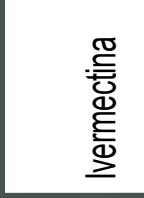 & 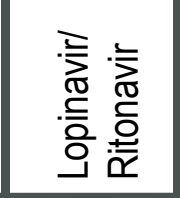 & 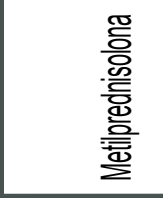 & 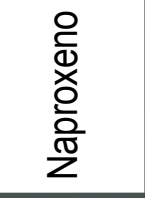 & 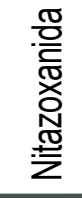 & 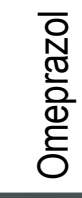 & 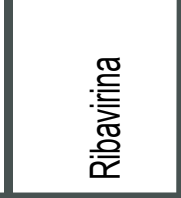 & 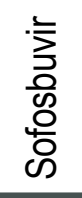 & 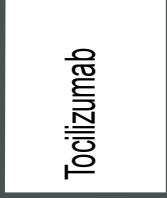 \\
\hline Hidroxicloroquina & & & & & & & & & $\begin{array}{l}\text { Riesgo de } \\
\text { toxicidad } \\
\text { aditiva }\end{array}$ & $\begin{array}{l}\text { Mayor } \\
\text { riesgo } \\
\text { de } \\
\text { neuro- } \\
\text { toxicidad }\end{array}$ & $\begin{array}{l}\text { Riesgo de } \\
\text { prolongación } \\
\text { del intervalo } \\
\text { QT debido a } \\
\text { que ambos } \\
\text { fármacos } \\
\text { tienen riesgo } \\
\text { prolongación } \\
\text { del intervalo } \\
\text { QT }\end{array}$ & & & & & $\begin{array}{c}\text { Riesgo } \\
\text { toxicidad } \\
\text { hematológica } \\
\text { aditiva }\end{array}$ & & $\begin{array}{l}\text { Posible } \\
\text { toxicidad } \\
\text { aditiva }\end{array}$ \\
\hline Interferón & & & & & & & & & & & & & & & & & & $\begin{array}{c}\text { Riesgo } \\
\text { toxicidad } \\
\text { hematologica } \\
\text { adiliva }\end{array}$ \\
\hline Ivermectina & & & & & & & & & & & $\begin{array}{l}\text { Mayor riesgo } \\
\text { de } \\
\text { neurotoxiciciad }\end{array}$ & & & & & & & \\
\hline $\begin{array}{l}\text { Lopinavir/ } \\
\text { Ritonavir }\end{array}$ & & & & & & & & & & & & $\begin{array}{l}\text { Aumentio del } \\
\text { riesgo de } \\
\text { efétos } \\
\text { secundarios } \\
\text { relacionados } \\
\text { con los } \\
\text { esteroides }\end{array}$ & & & & & & \\
\hline Metiprednisolona & & & & & & & & & & & & & $\begin{array}{c}\text { Riesgo de } \\
\text { ülcera o } \\
\text { hemorragia } \\
\text { gastriontestinal. }\end{array}$ & & & & & \\
\hline Naproxeno & & \multirow{4}{*}{\multicolumn{4}{|c|}{$\begin{array}{l}\text { No coadministrar } \\
\text { Interacción potencial } \\
\text { Interacción potencial débil } \\
\text { No se espera interacción } \\
\uparrow \text { Aumento } \\
\downarrow \text { Disminución }\end{array}$}} & & & & & & & & & & & & & \\
\hline Nitazoxanida & & & & & & & & & & & & & & & & & & \\
\hline Omeprazol & & & & & & & & & & & & & & & & & & \\
\hline Ribavirina & & & & & & & & & & & & & & & & & & $\begin{array}{c}\text { Riesgo de } \\
\text { toxiciddad } \\
\text { hematologica } \\
\text { adiliva }\end{array}$ \\
\hline Sofosbuvir & & & & & & & & & & & & & & & & & & \\
\hline Tocilizumab & & & & & & & & & & & & & & & & & & \\
\hline
\end{tabular}


Cuadro 2. Posibles interacciones fármaco-fármaco entre medicamentos evaluados para tratar el COVID-19 y fármacos comúnmente utilizados para tratar otras enfermedades

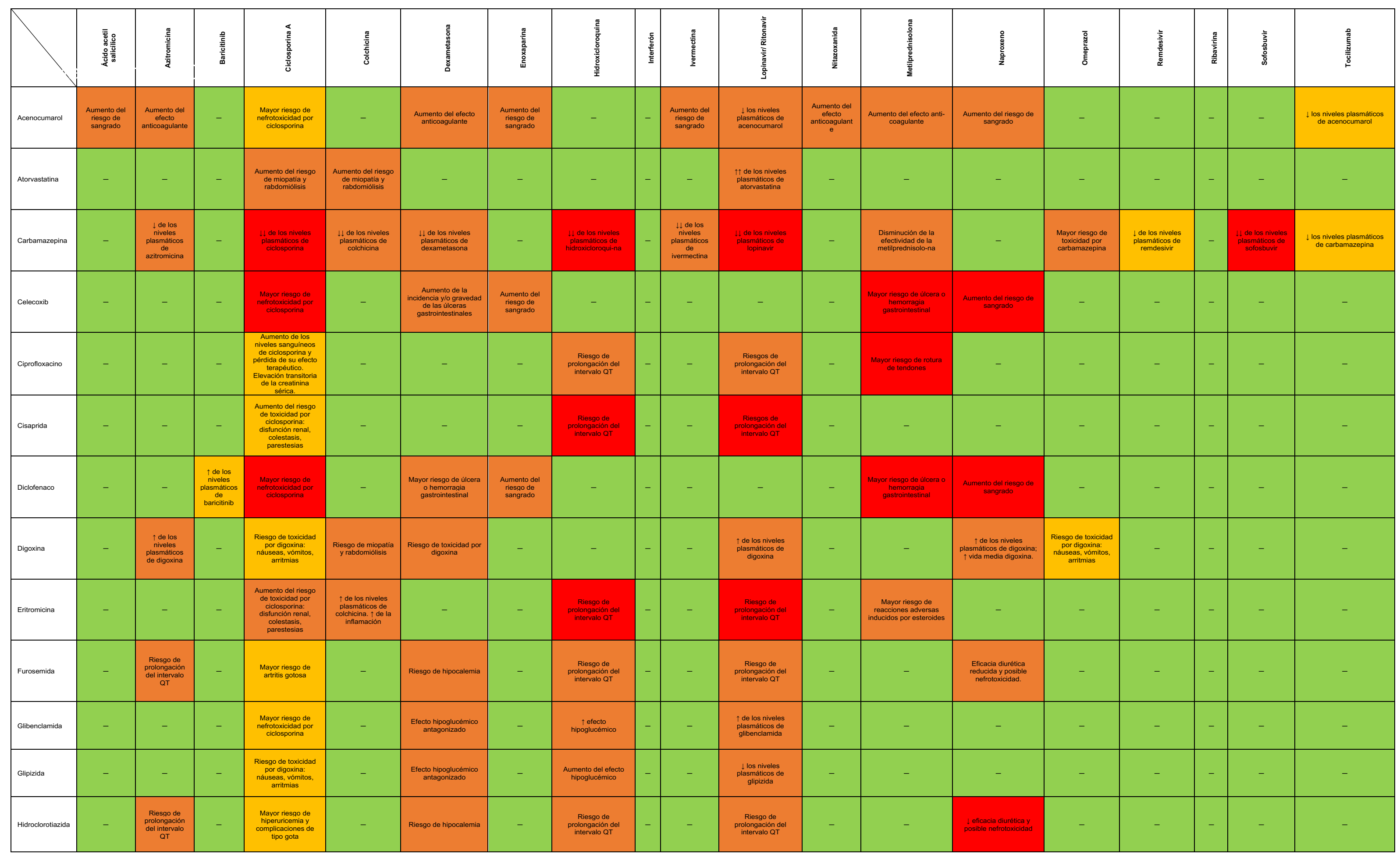

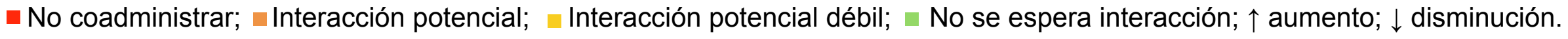


Cuadro 2. Posibles interacciones fármaco-fármaco entre medicamentos evaluados para tratar el COVID-19 y fármacos comúnmente utilizados para tratar otras enfermedades

\begin{tabular}{|c|c|c|c|c|c|c|c|c|c|c|c|c|c|c|c|c|c|c|c|}
\hline & 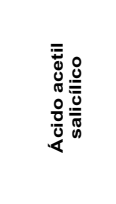 & 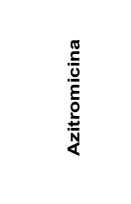 & 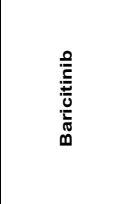 & 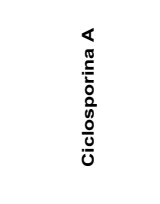 & $\begin{array}{l}\frac{\pi}{0} \\
\frac{0}{0} \\
\frac{0}{0} \\
0\end{array}$ & 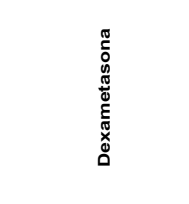 & 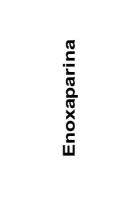 & 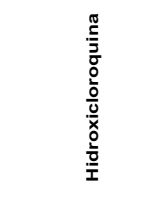 & 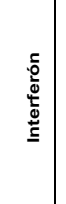 & 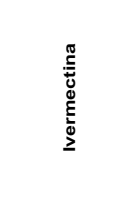 & 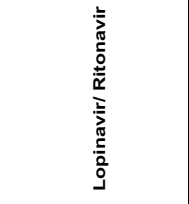 & 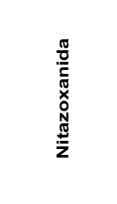 & 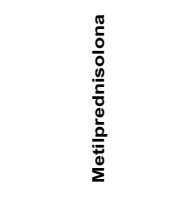 & $\begin{array}{l}\frac{0}{0} \\
\frac{0}{0} \\
\frac{0}{0} \\
\frac{0}{20} \\
\frac{0}{2}\end{array}$ & 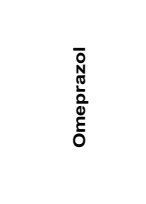 & 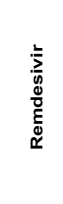 & 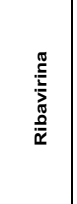 & 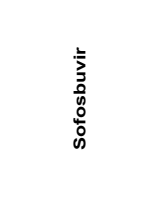 & 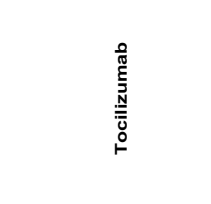 \\
\hline | Ibuprofeno & - & - & 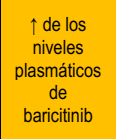 & $\begin{array}{l}\text { Mayor riesgo de } \\
\text { nefrotoxicicidad por } \\
\text { ciclosporina }\end{array}$ & - & $\begin{array}{l}\text { Aumento de la } \\
\text { incidencia alo gravedad } \\
\text { de las ulcerasas } \\
\text { gastrointestinales }\end{array}$ & $\begin{array}{l}\text { Aumento del } \\
\text { riesgo de } \\
\text { sangrado }\end{array}$ & - & - & - & - & - & $\begin{array}{c}\text { Mayor riesgo de delcera o } \\
\text { hemroragia } \\
\text { gastrointestinal }\end{array}$ & $\begin{array}{l}\text { Aumentito del riesgo de } \\
\text { sangrado }\end{array}$ & - & - & - & - & - \\
\hline | Itraconazol & - & - & - & $\begin{array}{l}\text { Aumento del riesgo } \\
\text { de toxicidad por } \\
\text { ciclosporina: } \\
\text { disfunción renal, } \\
\text { colestasis, } \\
\text { parestesias }\end{array}$ & 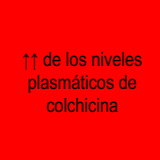 & - & - & $\begin{array}{c}\text { Riesgod de } \\
\text { probongacion nel } \\
\text { intervalo QT }\end{array}$ & - & $\begin{array}{l}\text { Mayor riesgo } \\
\text { de } \\
\text { neuroticicida } \\
d\end{array}$ & 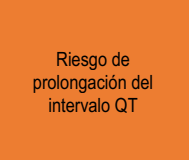 & - & - & - & $\begin{array}{l}\text { I de los niveles } \\
\text { plassáticos de } \\
\text { itracononazol }\end{array}$ & - & - & - & - \\
\hline Litio & - & $\begin{array}{l}\text { Riesgo de } \\
\text { probongación } \\
\text { del iniervalo } \\
\text { QT }\end{array}$ & - & - & - & $\begin{array}{l}\text { Excreción alterada del } \\
\text { Ilitio }\end{array}$ & - & $\begin{array}{c}\text { Riesgoo de } \\
\text { prolorgación del } \\
\text { intervalo QT }\end{array}$ & - & - & $\begin{array}{c}\text { Riesgo de } \\
\text { prolongación del } \\
\text { intervalo QT }\end{array}$ & - & - & $\begin{array}{l}\text { Aumento de la toxicidad } \\
\text { del litio }\end{array}$ & - & - & - & - & - \\
\hline Metformina & - & - & - & - & - & $\begin{array}{l}\text { Efectoto hipogluluémico } \\
\text { antagonizado }\end{array}$ & - & $\begin{array}{l}\text { Tefecto } \\
\text { hipoglucémico }\end{array}$ & - & - & - & - & - & - & - & - & - & - & - \\
\hline Nifedipina & - & 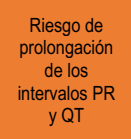 & - & - & - & - & - & $\begin{array}{l}\text { Riesgo de } \\
\text { prolongación de los } \\
\text { intervalos } P R \text { y QT }\end{array}$ & - & - & $\begin{array}{c}\text { Riesgo de } \\
\text { prolongación del } \\
\text { intervalo PR }\end{array}$ & - & - & - & - & - & - & - & - \\
\hline Pravastatina & - & - & - & - & $\begin{array}{l}\text { Aumento del riesgo } \\
\text { de miopotiay } \\
\text { rabdomiólisis }\end{array}$ & - & - & - & - & - & - & - & - & - & - & - & - & - & - \\
\hline \begin{tabular}{|l|} 
Sildenafil \\
\end{tabular} & - & - & - & - & - & - & - & - & - & - & 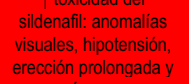 & - & - & - & - & - & - & - & - \\
\hline Tramadol & - & $\begin{array}{l}\text { Riessgo de } \\
\text { prolongación } \\
\text { del iniervalo } \\
\text { QT }\end{array}$ & - & - & - & - & - & $\begin{array}{l}\text { Riessodo de } \\
\text { prolongación del } \\
\text { intervalo QT }\end{array}$ & - & - & $\begin{array}{c}\text { Riesgo de } \\
\text { prolongación del } \\
\text { intervalo QT }\end{array}$ & - & - & - & - & - & - & - & - \\
\hline \begin{tabular}{|l|} 
Verapamil \\
\end{tabular} & - & - & - & - & $\begin{array}{l}\text { Ide los niveles } \\
\text { plasmáticos de } \\
\text { colchicicia }\end{array}$ & - & - & $\begin{array}{l}\text { Riesgo de } \\
\text { prolongacion de los } \\
\text { intervalos PR y QT }\end{array}$ & - & 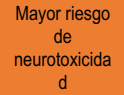 & - & - & - & - & - & - & - & - & - \\
\hline Warfarina & $\begin{array}{l}\text { Aumento del } \\
\text { riesgo de } \\
\text { sangrado }\end{array}$ & $\begin{array}{l}\text { Aumentio del } \\
\text { efecto } \\
\text { anticagaulante }\end{array}$ & - & - & - & $\begin{array}{c}\text { Aumento del efecto } \\
\text { anticoagulante }\end{array}$ & $\begin{array}{l}\text { Aumento del } \\
\text { riesgo de } \\
\text { sangrado }\end{array}$ & - & - & $\begin{array}{c}\text { Aumento del } \\
\text { riesso de } \\
\text { sangrado }\end{array}$ & $\begin{array}{l}\text { Iniveles plasmáticos } \\
\text { de warfarina }\end{array}$ & $\begin{array}{l}\text { Aumento del } \\
\text { efectol } \\
\text { anticoagulant } \\
e\end{array}$ & - & $\begin{array}{l}\text { Aumentit del ressgo de } \\
\text { sangrado }\end{array}$ & - & - & $\begin{array}{c}\text { Aume } \\
\text { nto } \\
\text { del } \\
\text { efectio } \\
\text { antico } \\
\text { agula } \\
\text { nte }\end{array}$ & $\begin{array}{l}\text { Modificación del } \\
\text { efétod de la } \\
\text { warafina }\end{array}$ & $\begin{array}{l}\text { Modificación del éfecto de } \\
\text { la warfarina }\end{array}$ \\
\hline
\end{tabular}

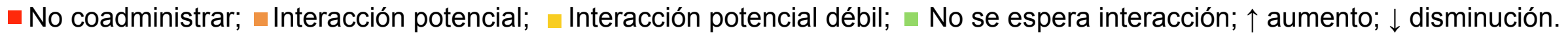


intensidad débil con monitoreo o ajuste de dosis que probablemente no sea necesario; (3) interacción potencial clínicamente significativa que puede requerir un estrecho seguimiento, la alteración de la dosis de alguno de los fármacos o el momento de administración; y (4) los medicamentos no deben coadministrarse.

La coadministración de algunos fármacos utilizados para el tratamiento de COVID-19 o de fármacos para tratar comorbilidades puede interaccionar con el lopinavir/ritonavir debido a que es un inhibidor de la enzima CYP3A4 y puede conducir a una elevación de los niveles plasmáticos cuyo resultado puede ser la aparición de reacciones adversas de los fármacos metabolizados por esta enzima.

Tanto la azitromicina como la hidroxicloroquina son fármacos utilizados en el marco del tratamiento con COVID-19 que pueden causar una prolongación del intervalo QT que, en presencia de algunos fármacos, como la cisaprida, pueden aumentar el riesgo de taquicardia ventricular polimórfica (torsades de pointes), síncope, y muerte súbita.

La administración sistémica de glucocorticoides exacerban la hiperglucemia en personas con diabetes, pueden desenmascarar la diabetes no diagnosticada y, en aquellos con riesgo de diabetes, es posible que precipiten hiperglucemia y diabetes de nueva aparición comúnmente denominada diabetes inducida por esteroides. ${ }^{14}$ En el contexto de la COVID-19, la dexametasona y la metilprednisolona pueden antagonizar el efecto hipoglucemiante de fármacos utilizados para controlar la glucemia de los pacientes diabéticos.

Los fármacos que utilizan los mismos transportadores para distribuirse en el organismo pueden interaccionar, provocando el aumento de los niveles plasmáticos de uno o ambos fármacos y favorecer la aparición de reacciones adversas. Tal es el caso entre la ciscloporina, un inhibidor de la glicoproteína $\mathrm{P}$, y la ivermectina cuya interacción se puede manifestar por la neurotoxicidad inducida por esta última.

En el contexto de la emergencia sanitaria, las IM pueden representar una causa importe de morbilidad e incremento en la letalidad, por tal razón, es importante considerarlas al momento de tomar decisiones farmacoterapéuticas para el tratamiento de la COVID-19.

\section{REFERENCIAS}

1. Chilamakuri R, Agarwal S. COVID-19: Characteristics and therapeutics. Cells. 2021; 10: 206. doi: 10.3390/cells10020206

2. Frequently asked questions for Veklury (remdesivir). Food and Drug Administration. 2020. Disponible en: https://www.fda.gov/media/137574/download

3. WHO. Solidarity Trial Consortium. Repurposed antiviral drugs for Covid-19 - Interim WHO Solidarity Trial results. N Engl J Med. 2021;384: 497-511. doi: 10.1056/NEJMoa2023184.

4. Comisión Federal para la Protección contra Riesgos Sanitarios. COFEPRIS emite autorización para uso de emergencia de Remdesivir. México: COFEPRIS;2021. Disponible en: https://www.gob.mx/cofepris/articulos/cofepris-emite-autorizacion-para-uso-de-emergencia-de-remdesivir?state=published 
5. Food and Drug Administration. FDA cautions against use of hydroxychloroquine or chloroquine for COVID-19 outside of the hospital setting or a clinical trial due to risk of heart rhythm problems. FDA. 2020.

6. Padhy BM, Mohanty RR, Das S, Meher BR. Therapeutic potential of ivermectin as add on treatment in COVID 19: A systematic review and meta-analysis. J Pharm Pharm Sci. 2020;23:462-469.

doi: 10.18433/jpps31457.

7. Meneses Calderón J, Figueroa Flores MDR, Paniagua Coria L, Briones Garduño JC, Meneses Figueroa J, Vargas Contretas MJ, et al. Nitazoxanide against COVID-19 in three explorative scenarios. J Infect Dev Ctries. 2020;14(9):982-986. doi: 10.3855/jidc.13274.

8. Roche provides an update on the phase III COVACTA trial of Actemra/RoActemra in hospitalised patients with severe COVID-19 associated pneumonia. Disponible en: https://www.roche.com/investors/updates/inv-update-2020-07-29.htm

9. Secretaría de Salud. Uso de dexametasona en pacientes hospitalizados por COVID-19. México: Secretaría de Salud. Comisión Coordinación de Institutos Nacionales de Salud y Hospitales de Alta Especialidad. Disponible en: https://coronavirus.gob.mx/wp-content/uploads/2020/08/Uso_dexamtasona.pdf

10. Gálvez-Romero JL, Palmeros-Rojas O, Real-Ramírez FA, Sánchez-Romero S, Tome-Maxil R, Ramírez-Sandoval MP, et al. Cyclosporine A plus low-dose steroid treatment in COVID-19 improves clinical outcomes in patients with moderate to severe disease: A pilot study. J Intern Med. 2020:10.1111/joim.13223. doi: 10.1111/joim.13223.

11. Secretaría de Salud. Uso de medicamentos de eficacia no demostrada contra covid-19. México: Secretaría de Salud. Comisión Coordinación de Institutos Nacionales de Salud y Hospitales de Alta Especialidad. Disponible en: https://coronavirus.gob.mx/wp content/uploads/2020/08/Uso_medicamientos_COVID_5Ago2020.pdf

12. Hajjar ER, Cafiero AC, Hanlon JT. Polypharmacy in elderly patients. Am J Geriatr Pharmacother. 2007;5(4):345-351. doi: 10.1016/j.amjopharm.2007.12.002.

13. University of Liverpool. COVID-19 Drug Interactions. Liverpool: Reino Unido; 2021. Disponible en: https://www.covid19-druginteractions.org/

14. Rayman G, Lumb AN, Kennon B, Cottrell C, Nagi D, Page E, et al. Dexamethasone therapy in COVID-19 patients: implications and guidance for the management of blood glucose in people with and without diabetes. Diabet Med. 2021;38(1):e14378. doi: 10.1111/dme.14378. Available from: https://onlinelibrary.wiley.com/doi/10.1111/dme.14378

Castelán-Martínez OD. Tratamiento para la COVID-19(III) ¿Cuáles son los riesgos de interacciones medicamentosas? CyRS. 2021;3 (1 Suppl. 2): 1-14.DOl: https://doi.org/10.22201/fesz.26831422e.2021.3.1_suppl_3

\section{Suplemento Boletín de la evidencia de la Revista Casos y Revisiones de Salud}

Coordinador: Dr. Víctor Manuel Mendoza Núñez Información: Dr. Víctor Manuel Mendoza Núñez Diseño e ilustración: Catalina Armendáriz Beltrán
Facultad de Estudios Superiores Zaragoza, Campus I, Av. Guelatao \#66, Col. Ejército de Oriente, Alcaldía Iztapalapa, C.P. 09230, Ciudad de México

Tels.: 56230700 ext. 30770. Email: castelan@unam.mx 